\title{
Informed consent for penile prosthesis surgery
}

\author{
Jason R. Kovac \\ Men's Health Center, Indianapolis, Indiana, USA \\ Correspondence to: Dr. Jason R. Kovac, MD, PhD, FACS, FRCSC. Men's Health Center, 8240 Naab Road, Suite 220, Indianapolis, Indiana, 46260, \\ USA. Email: jkovac@urologyin.com. \\ Comment on: Narang GL, Figler BD, Coward RM. Preoperative counseling and expectation management for inflatable penile prosthesis implantation. \\ Transl Androl Urol 2017;6:S869-80.
}

Submitted Nov 13, 2017. Accepted for publication Nov 13, 2017.

doi: $10.21037 /$ tau.2017.11.17

View this article at: http://dx.doi.org/10.21037/tau.2017.11.17

The gold standard treatment for end-stage erectile dysfunction (ED) is the placement of a penile prosthesis. Informed consent is critical in helping to set expectations for this surgical procedure. All surgeons must help patients establish a solid understanding of the risks and benefits of the proposed treatment.

Informed consent is a legal concept where the treating physician must seek the authorization of his patient to perform a particular operation or intervention. The patient must be able to render an intelligent and informed decision based on all of the facts and information available (1). This decision needs to be made prior to the commencement of any intervention and should be based upon an understanding of the risks or hazards that would influence a reasonable person making a decision to give, or withhold consent (1).

The physician needs to disclose to the patient the potential for death, serious harm and other complications associated with the proposed procedure in lay terms. The physician must disclose available choices with regards to the proposed treatments. There is no duty to discuss minor risks inherent in the procedure. As long as the physician has thoroughly discussed the aforementioned issues with the patient, a nurse of physician assistant could have the patient sign the informed consent at a later time.

Based on a paper by Narang et al. (2), the following example for a penile prosthesis informed consent has been devised.

We had a thorough discussion about all the alternatives in the treatment of erectile dysfunction (ED). In addition to the penile implant, I made sure we discussed pills such as PDE5 inhibitors (Levitra/Viagra/Cialis/Stendra) as well as injectable therapies,
MUSE, and vacuum erection devices. I stressed the risks and benefits as well as the pros and cons of each of these options extensively. In discussing penile implant surgery; I included the different types of penile implants (semi-rigid devices as well as inflatable 2- and 3-piece prostheses). I repeated on multiple occasions that penile implant surgery was the final step in the management of ED therapy. The patient understood that once placed, one couldn't go back and attempt to use injections or pills and expect these treatments to work. The patient also understood that infection and device failure could result should the implant be injected. I went on to mention that there were 2 different brands of devices, Coloplast and AMS. To prevent infection, the AMS device was impregnated with antibiotics (Inbibizone ${ }^{T M}$; rifampin/ minocycline) and the Coloplast device was dipped into an antibiotic to coat it. He deferred to my judgment about which device to use in bis surgery.

The risks of penile prosthesis surgery were also discussed. It was a very long and frank discussion. First and foremost, infection was described as the most dreaded risk and complication. It occurs in $\sim 1-4 \%$ of all cases. Patients with spinal cord injuries as well as those with a history of long-term steroid use were at increased risk. Diabetes also conferred an elevated risk while smoking cessation decreased this risk. Should infection occur, the entire device would have to be removed. Should this be required, there would likely be corporal fibrosis, scarring, penile shortening as well as possible penile and scrotal disfigurement. I emphasized that I would do absolutely everything possible to reduce and mitigate this risk. If the device had to be removed then the patient would have the following options: immediate salvage procedure with reimplantation; delayed re-implantation or no future surgerythus leaving bim unable to have a natural erection. I went on to explain what this salvage procedure was. Basically, it would 
involve placement of a new device (malleable, 2- or 3-piece) following a complex set of irrigations and lavages; however, the infection risk from this salvage procedure was even higher, up to $30 \%$. I explained that this was a real and significant risk that needed to be considered. Other reasons to explant the device included erosion, persistent discomfort/pain and device malfunction.

I then detailed other risks of the operation including injury to the urethra, bladder, bowel and scrotal contents. Should these occur the operation might have to be aborted. I explained that rarely, vascular injury and significant bleeding could occur. If iliac vein injury occurred from reservoir placement, this could be catastrophic and result in potential death, major blood loss and lower limb loss in severe instances. I stressed that penile shortening would occur to a variable degree. This can be perceived as quite significant in some individuals. Some of this is due to lack of glans engorgement and MUSE/PDESi's could be used post-operatively to compensate. I also showed him his stretched penile length to give an indication of possible size following implantation.

Next, I explained the risk of dissatisfaction with the cosmetic and/or functional result of the device. In brief, he may simply be unhappy with the result. I also notified him that difficulties in being able to use the device and pump were also possible. I explained that while some men obtain good erections using the device post surgery, they could have changes in sensation, anorgasmia, and dissatisfaction with sex in general. I made sure he verbalized and demonstrated a good understanding of these points. Next, I explained the risk of device breakage or failure. Should this occur, future operations might be needed to fix device tubing, breaks or fluid leaks. There was also a risk of auto-inflation of the device. Inability to successfully use the device due to technical considerations was possible. Patients may also bave an inability to use, or even find the pump post operatively. I stated that I would be available to teach and train him to use bis device. I would also be available to treat any other issues mentioned above.

During our discussion, the patient was awake, alert and oriented. He participated and understood the discussion. Prior to scheduling surgery, I made sure he verbalized all the risk and benefits as well as the pros and cons of the procedure. He had the ability to ask questions, and I explained to him what to expect from the surgery. The patient fully comprehended the risks of the surgery and was not subject to any medications, illnesses or other impairments that might have affected his ability to comprehend or understand what was discussed. I made sure the patient had access to literature and offered him the ability to speak with other patients to get a sense of what to expect; both pre- and postoperatively. After the detailed informed consent described above, the patient decided he would like to proceed with insertion of a malleable, or a 2- or 3-piece inflatable, penile prosthesis.

\section{Acknowledgements}

Special thanks to Dr. Andrew Kramer (University of Maryland) for providing the initial framework for the above consent.

\section{Footnote}

Conflicts of Interest: The author has no conflicts of interest to declare.

\section{References}

1. Nahrstadt BC. Informed consent for penile prosthesis. Int J Impot Res 2009;21:37-50.

2. Narang GL, Figler BD, Coward RM. Preoperative counseling and expectation management for inflatable penile prosthesis implantation. Transl Androl Urol 2017;6:S869-80.
Cite this article as: Kovac JR. Informed consent for penile prosthesis surgery. Transl Androl Urol 2017;6(Suppl 5):S881S882. doi: $10.21037 /$ tau.2017.11.17 